\title{
Effect of post-treatments on the fatigue behaviour of 316L stainless steel manufactured by laser powder bed fusion
}

\author{
Chola Elangeswaran ${ }^{\mathrm{a}, \mathrm{b}, *}$, Antonio Cutolo ${ }^{\mathrm{a}, \mathrm{b}}$, Gokula Krishna Muralidharan ${ }^{\mathrm{c}}$, Charlotte de Formanoir ${ }^{\mathrm{a}}$, Filippo Berto ${ }^{\mathrm{d}}$, \\ Kim Vanmeensel ${ }^{\mathrm{e}}$, Brecht Van Hooreweder ${ }^{\mathrm{a}}$ \\ ${ }^{a}$ KU Leuven, Department of Mechanical Engineering, Celestijnenlaan 300, 3001 Leuven, Belgium \\ ${ }^{b}$ SIM M3 Program, Technologiepark 935, 9052 Zwijnaarde, Belgium \\ c 3 D Systems Leuven, Grauwmeer 14, 3001, Leuven, Belgium \\ ${ }^{d}$ Norwegian University of Science and Technology (NTNU), Department of Mechanical and Industrial Engineering, 7491 Trondheim, Norway \\ ${ }^{e}$ KU Leuven, Department of Materials Engineering, Kasteelpark Arenberg 44, 3001 Leuven, Belgium
}

\begin{abstract}
This paper investigates the influence of post treatments on the fatigue properties of 316L stainless steel produced by laser powder bed fusion. Miniaturised fatigue samples are built in vertical orientation with optimised process conditions to result in very low porosities and minimal scatter in results. Fatigue performance is evaluated for two different material conditions: as-built and stress-relieved, at a nominal load ratio of -1 . Furthermore, the samples are tested with and without surface machining. A thorough microstructural and fractographic analysis is performed to evaluate the impact of the main fatigue influencing factors. The results show that the fatigue behaviour of machined samples with and without stress relief heat treatment exceeds that of conventionally manufactured 316L.
\end{abstract}

Keywords: Additive manufacturing, stainless steel, S-N curves, surface treatments, ductility

\section{Introduction}

Additive manufacturing (AM) finds itself steadily progressing from humble rapid prototyping origins towards industrial and large scale production scenarios [1,2]. The swift technological maturity implies the urgent need for validation of AM parts in complexly loaded applications. Laser powder bed fusion, one of the most widely used metal AM techniques, employs fine powder as feedstock and applies laser energy to selectively melt the material and build parts in layer-by-layer fashion [3, 4]. Selective laser melting (SLM) is a versatile laser powder bed fusion process capable of manufacturing dense parts with different ferrous and non-ferrous metals and alloys, for diverse applications [5]. SLM components in functional applications often undergo cyclic loading conditions, hence their fatigue behaviour needs to be fully understood [6].

\footnotetext{
${ }^{*}$ Corresponding author

Email address: chola.elangeswaran@kuleuven. be (Chola Elangeswaran)

URL: www. set.kuleuven. be/am/ (Chola Elangeswaran)
} 
316L stainless steel is a tough, ductile and corrosion resistant austenitic stainless steel, widely used in cyclically loaded components in a variety of engineering sectors such as automobile, construction, refinery, oil and gas, and chemical and petrochemical industries [7,8]. 316L is hot workable by most common techniques such as drawing, shearing and stamping, but machining to final shape is not considered easy due to its high work hardening behaviour, low thermal conductivity and high ductility. High surface roughness and tool wear are frequently reported during machining of austenitic stainless steels $[9,10]$. Hence a tool-less manufacturing process like AM offers immense potential to fabricate near net-shape $316 \mathrm{~L}$ parts.

Both academia and industry have already experimented with manufacturing 316L stainless steel parts by SLM. Saeidi et al. [8] built SLM 316L blocks of up to $98.6 \pm 0.1 \%$ relative density and investigated the microstructure and hardness. They observed an austenitic matrix composed of a columnar sub-grained microstructure. Liverani et al. [11] studied the influence of SLM process parameters on the microstructure and mechanical properties of 316L parts. Three different types of solidification defects influencing the resulting mechanical properties were observed, namely, binding defects, gas pores, and voids associated to residual stresses. They reported that binding defects could result from balling or inadequate laser energy while melting; gas pores were due to entrapment of gases during the process; and residual stress associated voids could be generated from small cracks forming along melt pool boundaries due to high thermal stresses, which thereby join with other cracks in proximity and separate from the solidified material to form voids. Yasa et al. [12] overcame such defects by performing laser re-melting and successfully built parts approaching $100 \%$ relative density.

Fatigue results of as-built SLM 316L reported in literature show lower performances than conventionally manufactured counterparts. SLM-processed 316L exhibits a finer microstructure and a higher yield strength, but often contains process-induced defects and reduced work hardening, leading to deteriorated fatigue properties in many instances [13]. Wrought 316L is usually strengthened for fatigue by cold working, surface carburization, surface nanostructuring, compressive stress introduction and similar methods [7, 14-16] which cannot always be applied to complex near-net shape SLM parts. Fatigue improvement strategies of SLM 316L are still at an infancy stage as the influence of existing post-treatments needs to be investigated in-depth. Figure 1 provides an overview of SN plots of vertically-built SLM 316L in their as-built condition or subjected to different combinations of heat treatments (annealing at $650^{\circ} \mathrm{C}$ for 2 hours or HIP at $1150^{\circ} \mathrm{C}$ and 1000 bar for 4 hours) and surface treatments (machining and polishing) [17]. The data points were extracted with a reasonable degree of accuracy from SN plots reported in literature. Test results from different loading conditions [18] were normalised to $\mathrm{R}=-1$ using Goodman's mean stress correction formula, which holds well for ductile metals [19]. For comparison, an SN plot of conventionally manufactured and machined 316L reported by Roland et al. [14] is also represented in Figure 1. These results show that heat treatments 
appear to have little influence on fatigue behaviour. Fatigue crack growth tests performed by Fergani et al. [20] also convey similar information. However, since the data are extracted from different sources with varying part quality and testing procedure, Figure 1 does not provide an unambiguous comparison between different post-treatments. In particular, stochastic amounts of defects could increase scatter and conceal the influence of other factors [21].

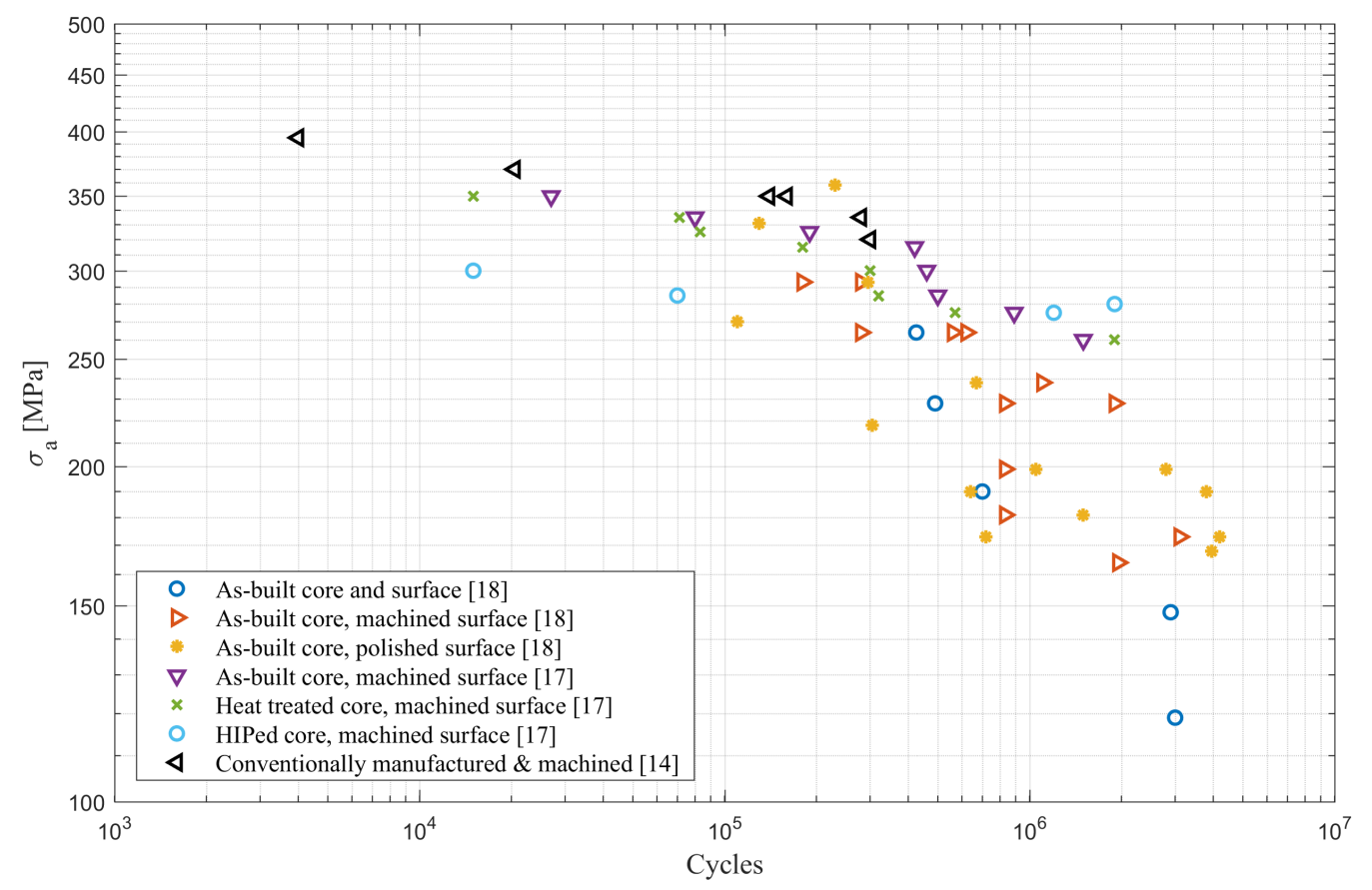

Figure 1: SN log-log plot for vertically-built SLM 316L subjected to different heat treatment and surface treatment combinations, compared with conventionally manufactured and machined $316 \mathrm{~L}$ (data extracted from references, normalised to $\mathrm{R}=-1$ )

This research systematically investigates the influence of post-treatments on the axial tension-compression fatigue performance of SLM 316L, while minimising the impact of process-induced defects. To guarantee high sample quality and consistency, all samples are built using the same, optimised process conditions resulting in very low residual porosities, so the scatter induced by varying amounts of defects is minimised. Fatigue performance is evaluated for two different material conditions: as-built (AB) and stress-relieved (SR). Furthermore, all samples are tested in nonmachined (NM) as well as machined (M) surface conditions. SLM parts tend to possess complex geometries and internal surfaces not easily accessible by surface treatments. Hence, recording the fatigue performance of parts without machining provides a realistic estimation for actual applications. A thorough microstructural and fractographic analysis of all samples is performed to evaluate the individual impact of fatigue influencing factors. 


\section{Materials and methods}

LaserForm $^{\circledR}$ 316L(A) stainless steel powder from 3D Systems, Inc. with chemical composition shown in Table 1 [22] was used as feedstock. A ProX ${ }^{\circledR}$ DMP 320 machine was used to produce the samples by 3D Systems, Inc, with the process parameters corresponding to officially released LaserForm ${ }^{\circledR} 316 \mathrm{~L}(\mathrm{~A})$ standard with $60 \mu \mathrm{m}$ layer thickness. The energy density of the parameters used, given by equation 1 , was $56 \mathrm{~J} / \mathrm{mm}^{3}$. Miniaturised fatigue samples with geometry shown in Figure 2 were built with their axis oriented along the vertical direction. This miniaturised geometry was designed by applying scaling laws [23] from ASTM E466 specifications for fatigue sample geometry, exclusively for additive manufacturing, considering the following factors: (i) optimised radius between the ends to minimise staircase effect on surface roughness; (ii) reduction of scatter in test results by ensuring failure of specimens at the smallest section; (iii) avoidance of buckling during axial compression loading; (iv) optimised gripping section for sufficient gripping force between sample and clamps; (v) reduction of production time and cost.

$$
\text { Energy density }=P / v \cdot h \cdot t
$$

where $\mathrm{P}$ is laser power $(\mathrm{W}), \mathrm{v}$ is scan velocity $(\mathrm{mm} / \mathrm{s}), \mathrm{h}$ is hatch spacing $(\mathrm{mm}), \mathrm{t}$ is layer thickness $(\mathrm{mm})$.

Table 1: Chemical composition of 316L stainless steel powder [22]

\begin{tabular}{ll}
\hline Element & Weight $\%$ \\
\hline $\mathrm{Fe}$ & Balance \\
$\mathrm{Cr}$ & $16.50-18.50$ \\
$\mathrm{Ni}$ & $10.00-13.00$ \\
$\mathrm{C}$ & $\leq 0.03$ \\
$\mathrm{Mn}$ & $\leq 2.00$ \\
$\mathrm{Mo}$ & $2.00-2.50$ \\
$\mathrm{~N}$ & $\leq 0.11$ \\
$\mathrm{Si}$ & $\leq 1.00$ \\
$\mathrm{P}$ & $\leq 0.045$ \\
$\mathrm{~S}$ & $\leq 0.03$ \\
\hline
\end{tabular}

Stress relief (SR) heat treatment was carried out at $470^{\circ} \mathrm{C}$ for 5 hours in argon atmosphere. For the machined surface condition, the samples were turned to required dimensions to attain a surface roughness of $0.5 \pm 0.06 \mu \mathrm{m}$ Ra. The non-machined samples exhibted an average surface roughness of $7.2 \pm 1.3 \mu \mathrm{m}$ Ra. The density of all the samples 


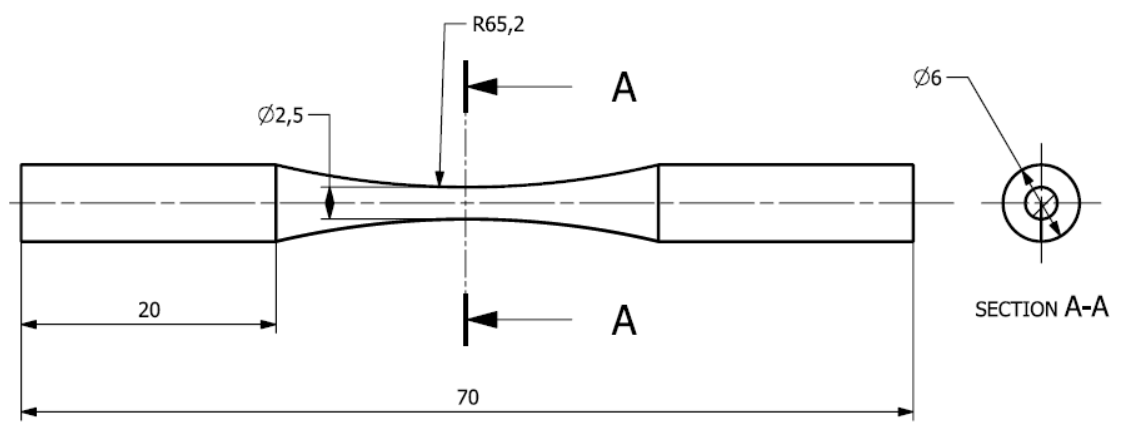

Figure 2: Fatigue sample geometry (all dimensions in $\mathrm{mm}$ )

was measured by Archimedes method and was found to be higher than $99.4 \pm 0.1 \%$ relative density, considering 8.0 $\mathrm{g} / \mathrm{cm}^{3}$ as the theoretical density of 316L. For microstructural characterisation, electrochemical etching was performed at 6V DC with $10 \%$ oxalic acid solution on ground and polished samples, followed by optical and scanning electron microscopy (SEM) using Keyence VHX 6000 and Philips XL30 FEG equipment, respectively.

A SHIMADZU AG-X Plus machine was used to perform the tensile tests as per ASTM E8M norms. The tests were performed at a strain rate of $0.5 \% / \mathrm{min}$ in the elastic part and $40 \% / \mathrm{min}$ in the plastic part. Specimens in four different combinations of material and surface conditions, as reported in Table 2, were tested for fatigue behaviour. Axial tension-compression fatigue tests at $\mathrm{R}=-1$ were performed with an Instron Electropuls E10000 machine. Force-controlled constant amplitude tests were conducted at $60 \mathrm{~Hz}$ until total fracture or run-out at 2,000,000 cycles. To determine the test frequency, a preliminary study was performed at 30 and $60 \mathrm{~Hz}$ by testing a minimum of two iterations per stress level for each frequency. The temperature at the smallest section was monitored with a contactless IR temperature sensor. No significant temperature difference or scatter in fatigue results was observed for the tests at the two frequencies. Hence $60 \mathrm{~Hz}$ was chosen as test frequency for all samples, considering the reduced testing time. Post-fracture SEM analysis was conducted to identify the crack initiation and propagation behaviour.

Table 2: Sample notations subjected to fatigue testing

\begin{tabular}{lll}
\hline Notation & Heat treatment & Surface treatment \\
\hline ABNM & As-built & Non-machined \\
SRNM & Stress relieved & Non-machined \\
ABM & As-built & Machined \\
SRM & Stress relieved & Machined \\
\hline
\end{tabular}




\section{Results}

\section{Microstructural characterisation}

Optical microscopic analysis of 316L stainless steel after SLM shows visibly distinct melt pools in Figure 3(a), representing the solidification pattern during selective melting. Within each melt pool, solidification takes place along the heat gradient, starting from the periphery and reaching towards the core. Cross sectional observation also shows a columnar grain growth pattern across melt pools along the building direction. Epitaxial solidification in layer-bylayer fashion during SLM results in such vertical columnar grains, indicated by arrow marks in Figure 3. After stress relief heat treatment, the melt pool boundaries and columnar grains still remain clearly visible, as seen in Figure 3(b). Overall, optical microscopy does not reveal any significant microstructural change resulting from this heat treatment.

Further microstructural observation using SEM shows a sub-grained cellular microstructure for as-built samples within the columnar grains, as seen in Figure 4(a). Very high cooling rates in SLM do not facilitate formation of equiaxed grains, thereby resulting in such a cellular pattern [24]. Cells with a diameter below $1 \mu \mathrm{m}$, growing cylindrically along different directions, can be seen on the cross section. Similar to as-built parts, a cellular microstructure was observed in SR specimens in Figure 4(b). SR was carried out at $470^{\circ} \mathrm{C}$, a temperature too low for recrystallization or major microstructural changes to occur. However, SEM analysis reveals that the stress relief heat treatment induces a slight coarsening of the cellular solidification morphology.
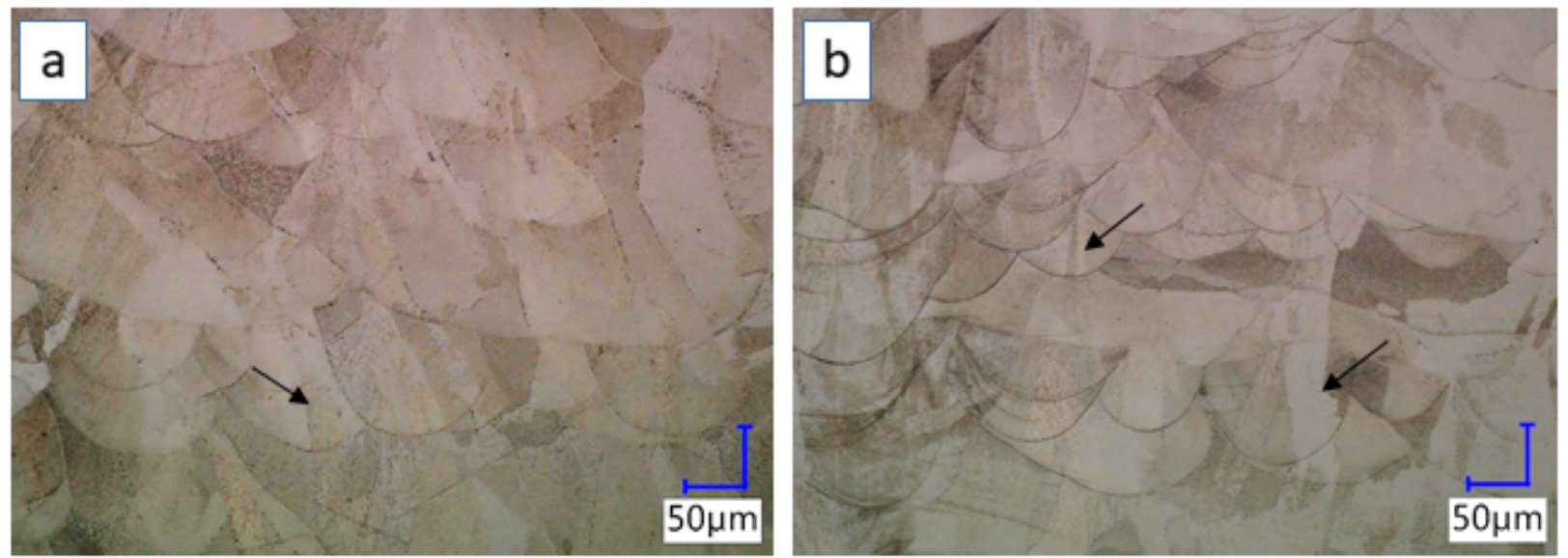

Figure 3: Optical microscopic images of 316L along building direction for as-built (a) and stress relieved (b) samples 

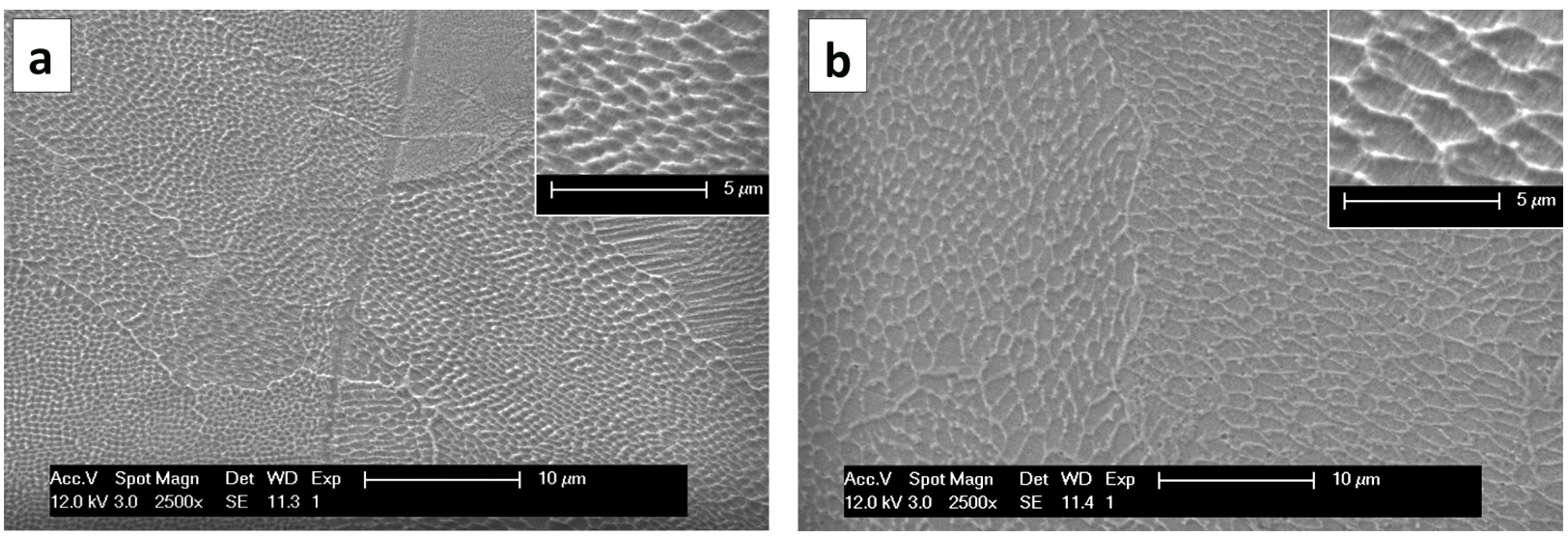

Figure 4: SEM images of SLM 316L in as-built (a) and stress relieved (b) conditions

\section{Tensile performance}

Table 3 shows the tensile results of SLM 316L for different heat treatment conditions along with those of conventionally manufactured 316L reported by Roland et al. [14]. As-built SLM 316L exhibits a good combination of tensile strength and ductility. Compared to conventional manufacturing, a higher yield strength and lower ductility are observed for SLM samples. This can be related to the Hall-Petch relationship and to the fact that wrought 316L exhibits coarse grained austenitic microstructure, whereas the fast cooling rates encountered in SLM lead to a fine grained microstructure as seen in Figure 3(a).

Stress relief has a marginal impact on the tensile properties, as it induces a minor strength reduction and ductility increase. This can be directly related to the very limited microstructural changes, i.e. slight cellular coarsening, resulting from SR. However, the difference in tensile properties is not statistically significant between the as-built and stress relieved conditions. Compared to conventionally manufactured samples, both these conditions exhibit higher strength and lower ductility values.

Table 3: Tensile results of SLM 316L in different conditions

\begin{tabular}{llll}
\hline Condition & $\sigma_{\mathbf{y}, \mathbf{0 . 2} \%}[\mathrm{MPa}]$ & UTS [MPa] & Elongation before fracture [\%] \\
\hline As-built & $453 \pm 6$ & $573 \pm 6$ & $46 \pm 1$ \\
Stress relief heat treated & $449 \pm 5$ & $570 \pm 5$ & $48 \pm 1$ \\
Conventionally manufactured [14] & 300 & 650 & 55 \\
\hline
\end{tabular}




\section{Fatigue performance}

Fatigue results of the samples in different conditions plotted in a log-log graph are shown in Figure 5. The data points are fitted with Basquin's equation shown in equation 2.

$$
\sigma_{\mathrm{a}}=\mathrm{A} \cdot\left(2 N_{\mathrm{f}}\right)^{\mathrm{b}}
$$

where $\sigma_{\mathrm{a}}$ is the stress amplitude, $2 \mathrm{~N}_{\mathrm{f}}$ is the number of cycles to failure, $\mathrm{A}$ and $\mathrm{b}$ are material constants.

The samples without surface treatment, namely ABNM and SRNM, exhibit very similar fatigue behaviour. Similar to the the tensile results, the fatigue performance shows no major variation between as-built and stress-relieved states. However, compared to as-built condition, the SN curve of stress relieved samples undergoes a slight decrease in slope, with the two SN curves intersecting at about 100,000 cycles. At high stress levels SRNM samples exhibit relatively better fatigue lives, whereas at lower stress levels, ABNM samples perform slightly superior.

The samples that underwent machining show a substantially improved fatigue performance in both as-built and stress relieved conditions. They also exhibit a significant change in slope of the SN curves as seen in Figure 5 . Similar to what is observed in the case of non-machined surface condition, the machined samples show comparable fatigue behaviour in as-built and stress relieved states. Both SN curves intersect at about 100,000 cycles and the SN curve of SRM specimens exhibit a slightly reduced slope compared to ABM specimens. Run-out at 2,000,000 cycles was observed for both ABM and SRM conditions. For comparison, data points of conventionally manufactured and machined samples from Roland et al. [14] and Huang et al. [25] are also shown in the graph. The samples tested by Roland et al. [14] were circular cross sectional ones tested at $10 \mathrm{~Hz}$ testing frequency. Fatigue results of rolled and butt welded samples with surface polished as per ASTM E466 specifications were reported by Huang et al. [25]. These were rectangular cross sectional samples tested at $20 \mathrm{~Hz}$ testing frequency. In both references $[14,25]$ the samples were tested under axial tension-compression loading at $R=-1$. Thus, the results show that machined $316 \mathrm{~L}$ produced by SLM exhibits superior fatigue behaviour in both as-built and stress relieved states compared to conventionally manufactured specimens.

The fracture surface of an ABNM specimen shown in Figure 6(a) displays multiple cracks initiating from the surface and propagating towards the core. The crack initiation and propagation zone is characterised by a radial flow pattern, whereas the final fracture zone exhibits dimples typical of ductile fracture. A closer look at one of the crack initiation points in Figure 6(b) shows that the crack originated from unfused powder particles attached to the surface. Presence of unfused powder particles across the surface leads to such multiple crack inititation points. Once initiated, fatigue crack propagation in a relatively ductile material is frequently characterised by a pattern of ripples called 


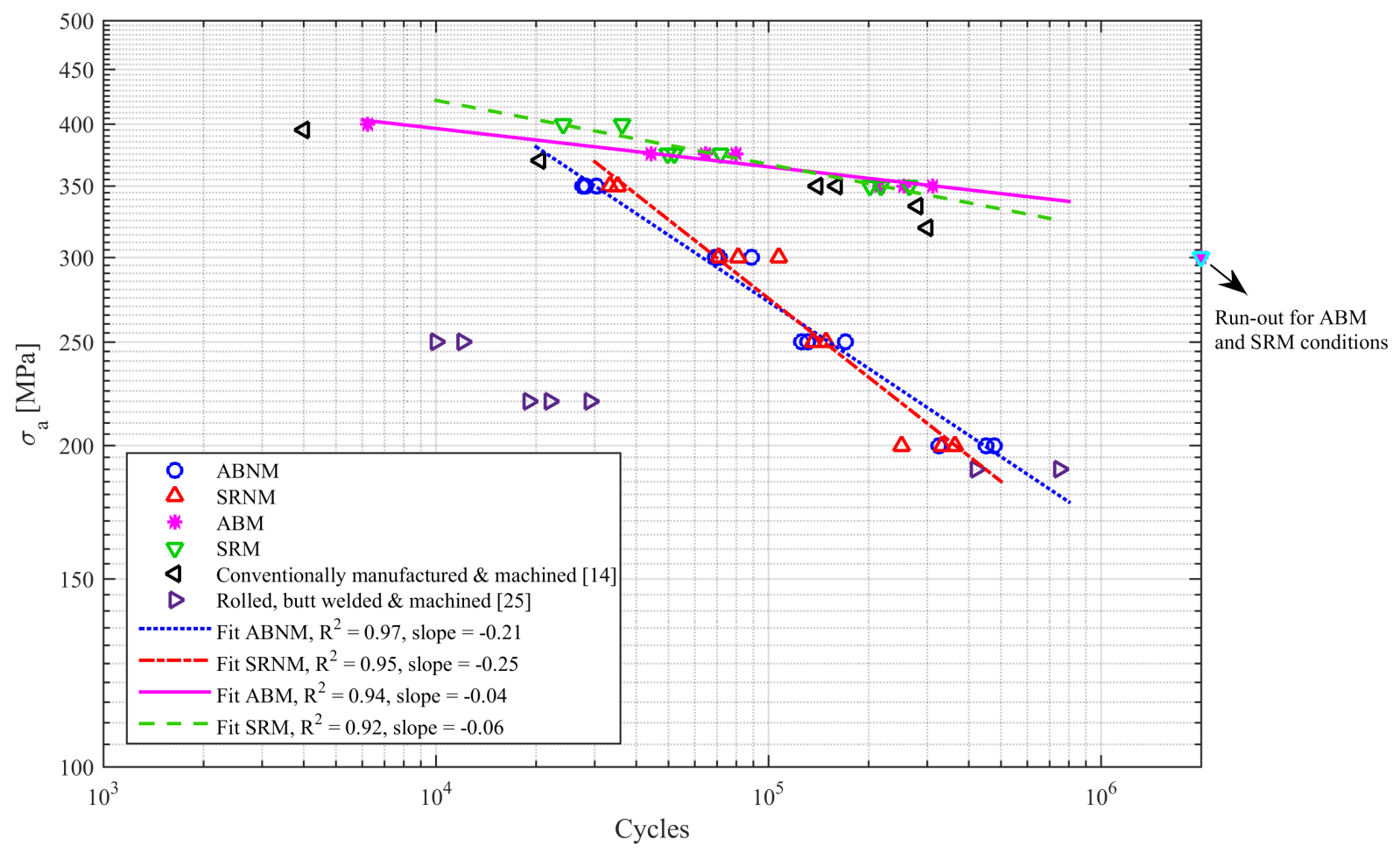

Figure 5: SN plot of SLM 316L stainless steel $(\mathrm{R}=-1)$

striations, representing successive positions of the advancing crack front. Such a striation pattern is shown in Figure 7 and is indicative of crack growth perpendicular to the loading direction. Fracture surfaces in Figures 6(c) and (d) indicate similar surface crack initiation and propagation behaviour for SRNM samples. Stress relieved samples also exhibited unfused powder particles on the surface, leading to multiple crack initiation sites and propagating towards the core. Representative fracture surface images are shown in Figure 6, but a complete observation of fracture surfaces from low to high life regimes indicated a stress-dependent fracture surface proportions. The ratio of crack initiation and propagation zone to final fracture zone increased as the stress level decreased. At low stress-high life regimes, the crack initiation and propagation zone occupied almost the entire cross section of the sample, leaving negligible final fracture region. Such a stress-dependent fracture surface proportion is in line with observations previously reported in literature, for example, by Kocanda [26].

Fracture surfaces of machined samples exhibit comparable crack initiation and propagation behaviour. Figures 8(a) and (b) depict crack initiation from the surface of an ABM sample. Not much difference is observed for the SRM samples with Figures 8(c) and (d) indicating a similar fatigue fracture phenomenon. Unlike the non-machined conditions, no unfused powder particles are observed in the machined samples. So multiple cracks initiations are not 
observed in these specimens. Under the applied fatigue loads, one crack seems to have intiitated, which eventually branched and resulted in fracture. The stress-dependent fracture surface proportions between crack initiation and propagation zone to final fracture zone is also observed here similar to non-machined samples. Low stress-high life samples showed negligible final fracture region.
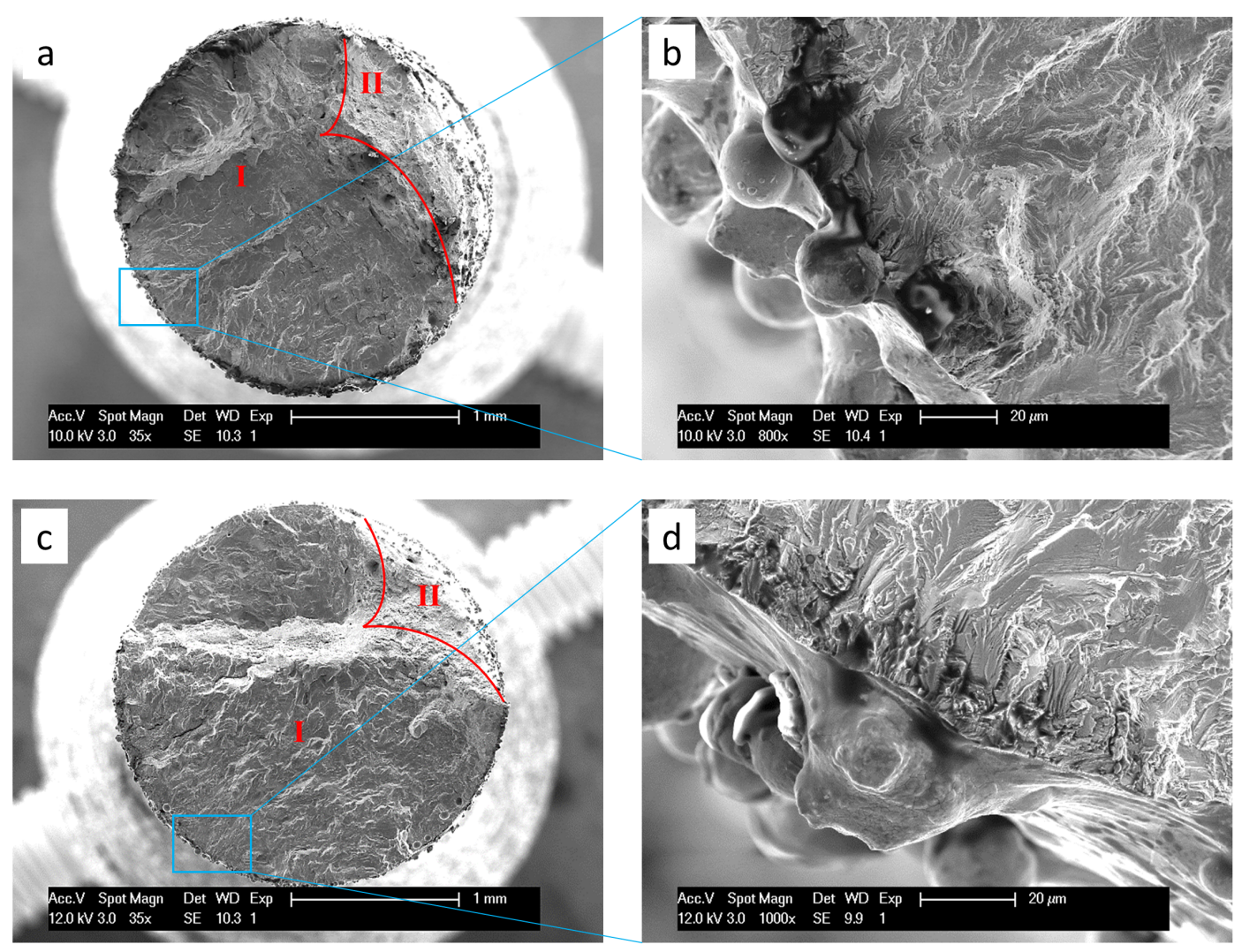

Figure 6: Fracture surfaces of ABNM [ $\sigma_{a}=350 \mathrm{MPa}, 28161$ cycles] (a), (b) and SRNM [ $\sigma_{a}=250 \mathrm{MPa}, 148663$ cycles $]$ (c), (d) samples; I: crack initiation and propagation zone, II: final fracture zone 

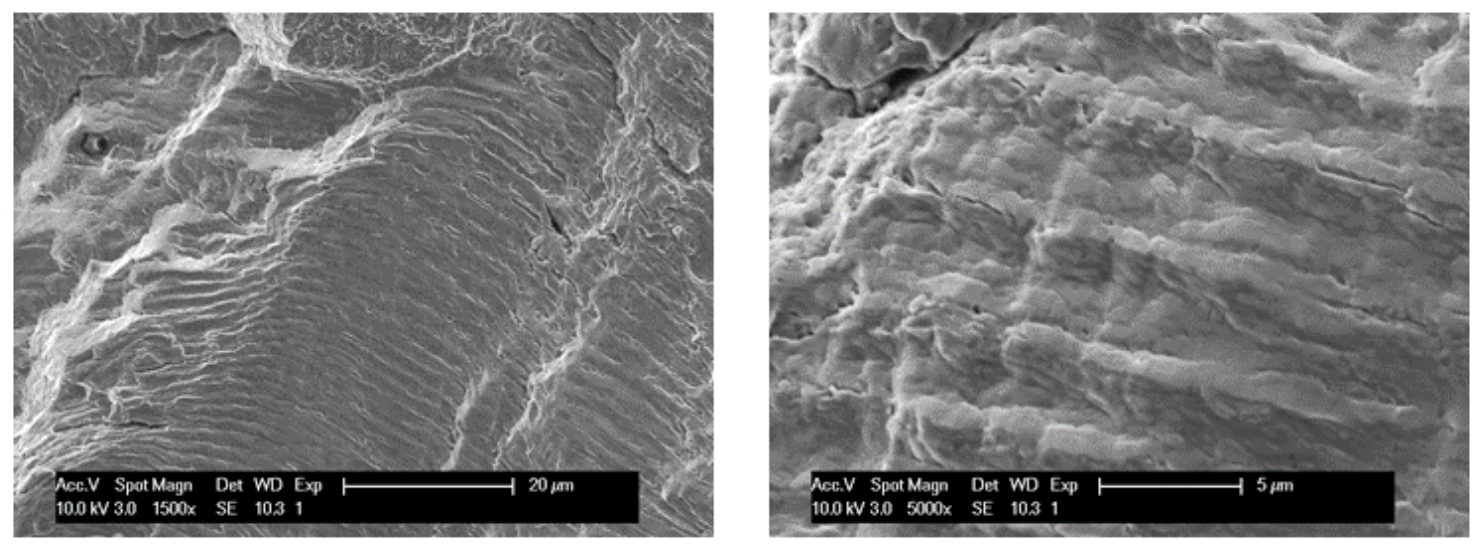

Figure 7: Striations in fatigue fracture surface of ABNM sample [ $\sigma_{a}=350 \mathrm{MPa}, 28161$ cycles]
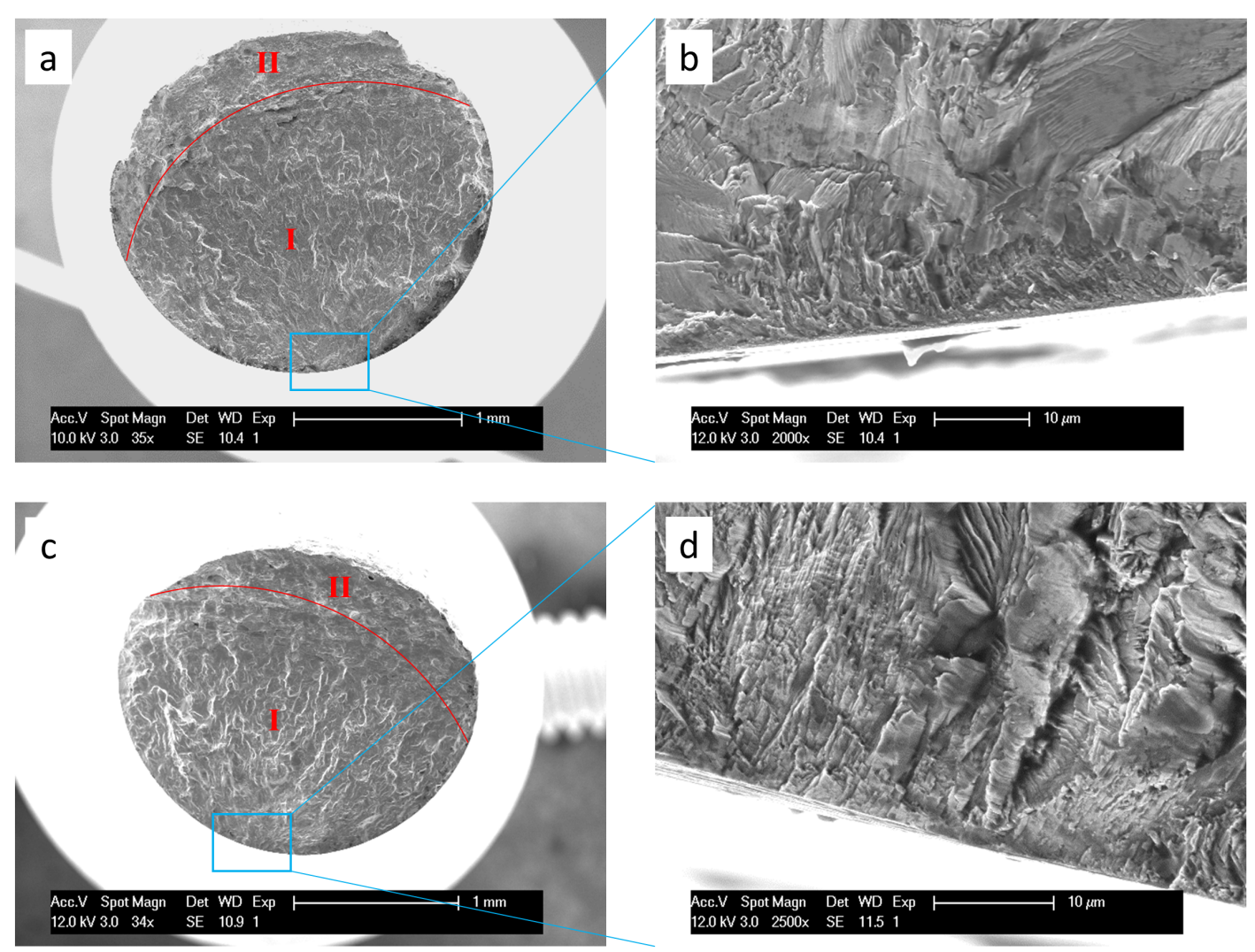

Figure 8: Fracture surfaces of ABM [ $\sigma_{a}=350 \mathrm{MPa}, 254980$ cycles] (a), (b) and SRM [ $\sigma_{a}=350 \mathrm{MPa}, 217990$ cycles $]$ (c), (d) samples; I: crack initiation and propagation zone, II: final fracture zone 


\section{Discussion}

Fatigue properties of SLM parts are a function of microstructure, residual stresses, surface finish, porosities and lack of fusion voids [27-29]. The present study does not investigate the influence of pores and voids, as the optimised manufacturing process yielded parts with a consistently high relative density. The SLM machine undergoes multiple vacuum passes before filling with inert gas, to maintain the building chamber free from oxide contaminants. Several cross sections of the samples were also investigated for porosity by optical microscopy. Such cross-sectional and fractographic examinations showed no obvious pores or lack of fusion voids to be responsible for sample failures. Moreover, Riemer et al. [30] reported that, owing to its high ductility, fatigue performance of $316 \mathrm{~L}$ is not significantly influenced by pores. Hence, the individual effect of the other above-mentioned fatigue influencing factors is evaluated for the vertically built miniaturised samples and described below, for each of the considered post-processing conditions.

\section{Fatigue behaviour of as-built samples}

The microstructure of the material, which directly impacts its strength and ductility, also influences its fatigue performance to some extent. Fatigue is mainly associated with localised plastic flow and hence a material with good plastic flow behaviour is expected to possess desirable fatigue properties [28, 31]. Plastic flow of a material is related to the mobility of dislocations. The extent of plastic flow determines a material's strength, as defined by resistance against dislocation motion, and ductility, which is the ability for dislocations to move and deform plastically. A material with a high yield strength absorbs a larger portion of applied stress or strain within its elastic strain regime, compared to a weaker material with the same elastic modulus. Plastic yielding and higher amount of plastic strain is observed in the latter [31]. A higher ductility, on the other hand, can help in avoiding sudden failure. Since strength and ductility are usually inversely related, an optimum balance between both needs to be selected for desired fatigue properties. Despite possessing relatively well-balanced tensile properties, namely $453 \pm 6 \mathrm{MPa}$ yield strength and $46 \pm 1 \%$ elongation at break, the as-built samples seem to exhibit a rather low fatigue life, which can be attributed to other influencing factors.

Non-machined SLM parts possess unmolten powder particles sintered to the surface, resulting in a rough surface. These particles act as stress concentrators and crack initiation sites. Under cyclic loading these points undergo high magnitudes of localised stresses compared to the applied nominal stress, resulting in local yielding and subsequent cracking.

\section{Influence of stress relief heat treatment}

Stress relieved SRNM samples undergo minimal changes in fatigue performance compared to as-built ones. Ther- 
mal treatment for 5 hours at $470^{\circ} \mathrm{C}$, i.e. well below the recrystallization temperature of $316 \mathrm{~L}$, does not induce significant microstructural changes, apart from a small cellular coarsening observed in Figure 3(b).

It can however be assumed that this specific treatment successfully relieves the residual stresses typically observed in as-built SLM 316L due to high cooling rates and temperature gradients [32, 33]. Despite this stress relief, the fatigue behaviour does not show any appreciable variation. Hence this result tends to indicate that the fatigue behaviour of SLM 316L stainless steel for the observed geometry is relatively insensitive to residual stresses, as previously observed by Leuders et al. [17].

316L exhibits relatively high ductility with an elongation at break of $46 \pm 1 \%$ and $49 \pm 5 \%$ in as-built and stressrelieved states, respectively. This indicates the ability to undergo a large amount of plastic deformation before complete fracture. As already mentioned, fatigue is a phenomenon involving localised plastic flow and deformation at favourable positions. Residual stresses usually superimpose the applied load and concomitant stress field, which act in a beneficial or detrimental way during micro-scale deformation, thereby influencing crack initiation and propagation behaviour. In edge-welded 316H stainless steel beam specimens, Mirzaee-Sisan et al. [34] recorded a relatively high fracture toughness of $130 \mathrm{MPa} \sqrt{m}$ and observed a crack length of $0.24 \mathrm{~mm}$. Extensive through-thickness plasticity with a plastic zone larger than $10 \mathrm{~mm}$ was observed. This large plastic zone suggests that residual stresses could get relieved due to the material's plasticity before crack initiation. Though SLM 316L does not exhibit such a high fracture toughness, a relatively high range of 63 to $87 \mathrm{MPa} \sqrt{m}$ was observed by Suryawanshi et al. [35]. Hence, such a high ductility and plasticity effects in 316L could explain the insensitivity of fatigue behaviour to residual stresses. However, such a conclusion is valid only at high stress levels when the applied load approaches the plastic limit load [36]. At lower stress levels where the applied loads are far below the yield strength, residual stresses could potentially influence the fracture behaviour. A thorough study on quantifying residual stresses and relating them with stress-dependent fatigue performance at very high cycle fatigue regime is still to be conducted.

It should however be highlighted that a small change in slope is observed between ABNM and SRNM samples in Figure 5. Their respective SN-curves intersect at around 100,000 cycles. Though the tensile results are not statistically different between the two conditions, they tend to show a small reduction in yield strength and increase in ductility after stress relief. This can be related to the slight coarsening taking place during SR. Generally when comparing fatigue behaviour between two metals with the same elastic modulus but with differing yield strength and ductility values, the fatigue responses intersect each other [31]. If A and B are two metals with yield strengths $\sigma_{\mathrm{A}}$ and $\sigma_{\mathrm{B}}$ and ductilities $\mathrm{D}_{\mathrm{A}}$ and $\mathrm{D}_{\mathrm{B}}$, respectively, such that $\sigma_{\mathrm{A}}<\sigma_{\mathrm{B}}$ and $\mathrm{D}_{\mathrm{A}}>\mathrm{D}_{\mathrm{B}}$, the fatigue behaviour will be as shown in Figure 9 [31]. At high applied stresses, the material's ductility predominantly governs the fatigue life, whereas at low stress levels, it is governed by the material's yield strength. 


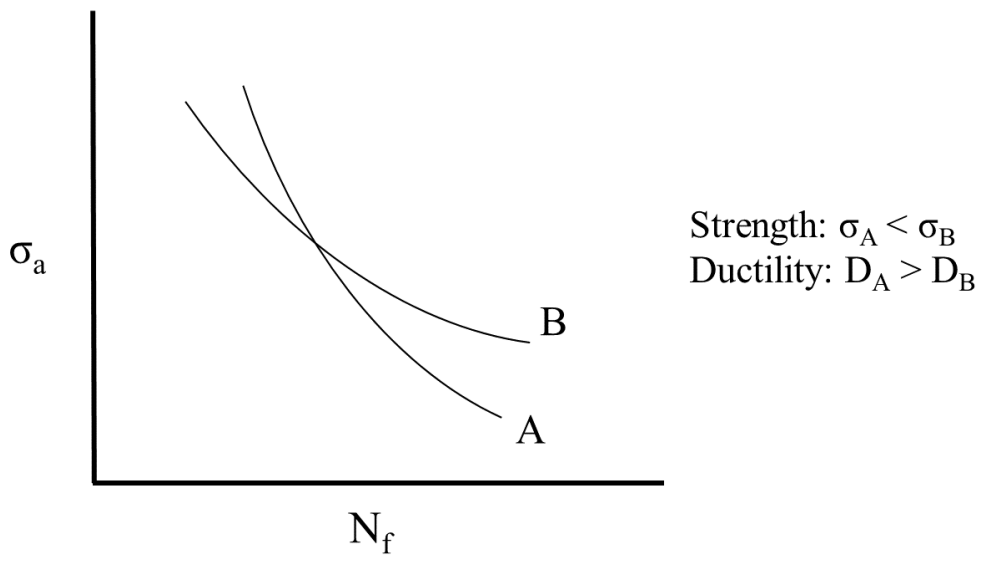

Figure 9: Fatigue response of two metals with differing strength and ductility [31]

At high applied loads, multiple cracks initiate from stress concentration points along the surface that undergo higher localised stresses than the nominal stress. One or few of these cracks develop into dominant or propagating cracks. Ductility plays a significant role at this stage, where a ductile material impedes the rate of crack growth and leads to longer fatigue life. In contrast, a strong and brittle material offers little resistance to crack propagation, which leads to fast fracture.

On the other hand, at low applied loads, fewer locations are exposed to localised stresses that are sufficiently high to induce crack initiation. Therefore, crack initiation dominates fatigue life in this case. As crack initiation depends on localised stresses approaching or exceeding the elastic limit, a material with higher yield strength performs better at low applied stresses, as illustrated in Figure 9. [31]

A similar trend as explained above is observed for SLM 316L in Figure 5. Though the difference is not very significant, the marginal variation can be explained by this phenomenon. ABNM and SRNM SN curves intersect at around $260 \mathrm{MPa}$ stress amplitude and 100,000 cycles. At stresses above $260 \mathrm{MPa}$, stress relieved samples with higher ductility possess better fatigue strengths, whereas below this value, the as-built counterparts with higher yield strength perform better. This result leads to an application-oriented conclusion: for components undergoing high stresses in application, heat treatment can be beneficial for its enhanced ductility. On the other hand, if the component is not subjected to high field stresses, as-built state can be preferred owing to its higher strength.

\section{Influence of surface treatment and combined heat treatment}

Both ABM and SRM conditions show superior fatigue resistance compared to conventionally manufactured samples [14]. Since all the samples were machined, this improved performance can be attributed to microstructural effects. High cooling rates in SLM lead to a fine grained microstructure compared to conventional manufacturing. The grain 
boundaries in such a fine grained microstructure offer high resistance against dislocation motion and crack propagation, enhancing the monotonic and fatigue strengths, respectively. Higher yield strength is also therefore observed compared to conventionally manufactured samples. Besides, all machined specimens show a significant performance improvement compared to non-machined ones. The initial high surface roughness of $7.2 \pm 1.3 \mu \mathrm{m} \mathrm{Ra}$, visible in Figures 6(b) and (d), was substantially decreased down to $0.5 \pm 0.06 \mu \mathrm{m} \mathrm{Ra}$ after machining. Under an applied cyclic load, activation of stress raisers along the surface leads to local stress concentration and microcrack initiation. In as-built SLM specimens, unfused powder particles attached to the surface along with inherent surface roughness act as such stress raisers. Machining removes these vulnerabilities from the surface to a large extent, hence resulting in delayed crack initiation and better fatigue performance. The slope of the SN curve on log-log scale is usually dependent on surface roughness when all other factors are constant. The finer the surface finish, the more horizontal the curve. It should be highlighted that ABM samples exhibit a run-out of 2,000,000 cycles at $300 \mathrm{MPa}$, i.e. around 52\% percent of the UTS. This shows the potential of achieving an endurance limit at around half the UTS.

SRM samples have a similar behaviour to ABM samples. A small change in slope is associated with SR, as previously observed for non-machined samples. The two SN curves intersect at around $360 \mathrm{MPa}$ and 100,000 cycles. At higher stress levels SR samples are more ductile and have better fatigue lives, while non-heat treated ones perform better at lower stress levels due to their higher yield strengths. Hence machined parts and components can be stress relieved when cyclically loaded above $360 \mathrm{MPa}$, and used without heat treatment for lower stress applications.

\section{Conclusion}

316L stainless steel manufactured by SLM can be post-processed using different heat or surface treatments resulting in varying fatigue behaviour. The optimal choice of the most appropriate treatments depends on the considered dynamically loaded application.

- In as-built material and non-machined surface condition, surface roughness largely influences the fatigue performance. Unfused powder particles attached to the surface act as stress raisers, leading to early crack initiation and lower fatigue lives.

- The removal of residual stresses via an SR heat treatment does not significantly influence the fatigue behaviour. Similar fatigue results of SR and as-built samples indicate a relative insensitivity of SLM 316L to residual stresses for the considered sample conditions.

- By removing critical crack initiators, machining significantly improves the fatigue performance. The fatigue behaviour of machined samples with and without stress relief heat treatment exceeded that of conventionally 
manufactured 316L for the considered cycle regime.

- To achieve desired fatigue performance, machined SLM 316L parts can be heat treated when cyclically loaded at high stresses (above $360 \mathrm{MPa}$ in this research), but can preferably be used in as-built state for lower stress applications.

\section{Acknowledgement}

The authors would like to acknowledge the financial support of SIM (Strategic Initiative Materials in Flanders) and VLAIO (Flemish government agency, Flanders Innovation \& Entrepreneurship) through the M3-FATAM project (HBC.2016.0446), part of the MacroModelMat (M3) research program, coordinated by Siemens (Siemens PLM software, Belgium).

\section{References}

[1] B. Vandenbroucke, J. Kruth, Selective laser melting of biocompatible metals for rapid manufacturing of medical parts, Rapid Prototyping Journal 13 (4) (2007) 196-203. doi:10.1108/13552540710776142.

[2] C. Weller, R. Kleer, F. T. Piller, Economic implications of 3D printing: Market structure models in light of additive manufacturing revisited, International Journal of Production Economics 164 (2015) 43-56. doi:10.1016/J.IJPE.2015.02.020.

[3] P. K. Gokuldoss, S. Kolla, J. Eckert, Additive Manufacturing Processes: Selective Laser Melting, Electron Beam Melting and Binder JettingSelection Guidelines., Materials (Basel, Switzerland) 10 (6). doi:10.3390/ma10060672.

[4] J. Kruth, P. Mercelis, J. Van Vaerenbergh, L. Froyen, M. Rombouts, Binding mechanisms in selective laser sintering and selective laser melting, Rapid Prototyping Journal 11 (1) (2005) 26-36. doi:10.1108/13552540510573365.

[5] D. Herzog, V. Seyda, E. Wycisk, C. Emmelmann, Additive manufacturing of metals, Acta Materialia 117 (2016) $371-392$. doi:10.1016/J.ACTAMAT.2016.07.019.

[6] P. Li, D. H. Warner, A. Fatemi, N. Phan, Critical assessment of the fatigue performance of additively manufactured Ti-6Al-4V and perspective for future research, International Journal of Fatigue 85 (2016) 130-143. doi:10.1016/j.ijfatigue.2015.12.003.

[7] H. Huang, Z. Wang, J. Lu, K. Lu, Fatigue behaviors of AISI 316L stainless steel with a gradient nanostructured surface layer, Acta Materialia 87 (2015) 150-160. doi:10.1016/J.ACTAMAT.2014.12.057.

[8] K. Saeidi, X. Gao, Y. Zhong, Z. J. Shen, Hardened austenite steel with columnar sub-grain structure formed by laser melting, Materials Science and Engineering A 625 (2015) 221-229. doi:10.1016/j.msea.2014.12.018.

[9] AZoM, Stainless Steel - Grade 316L (UNS S31603) (2004).

URL https : //www . azom. com/article. aspx?ArticleID=2382

[10] M. Kaladhar, K. V. Subbaiah, C. S. Rao, Machining of austenitic stainless steels - a review, International Journal of Machining and Machinability of Materials 12 (1/2) (2012) 178. doi:10.1504/IJMMM.2012.048564.

[11] E. Liverani, S. Toschi, L. Ceschini, A. Fortunato, Effect of selective laser melting (SLM) process parameters on microstructure and mechanical properties of 316L austenitic stainless steel, Journal of Materials Processing Technology 249 (2017) $255-263$. doi:10.1016/j.jmatprotec.2017.05.042. 
[12] E. Yasa, J.-P. Kruth, Microstructural investigation of Selective Laser Melting 316L stainless steel parts exposed to laser re-melting, Procedia Engineering 19 (2011) 389-395. doi:10.1016/J.PROENG.2011.11.130.

[13] J. Suryawanshi, K. G. Prashanth, U. Ramamurty, Mechanical behavior of selective laser melted 316L stainless steel, Materials Science and Engineering A 696 (January) (2017) 113-121. doi:10.1016/j.msea.2017.04.058.

[14] T. Roland, D. Retraint, K. Lu, J. Lu, Fatigue life improvement through surface nanostructuring of stainless steel by means of surface mechanical attrition treatment, Scripta Materialia 54 (11) (2006) 1949-1954. doi:10.1016/J.SCRIPTAMAT.2006.01.049.

[15] L. Ceschini, G. Minak, Fatigue behaviour of low temperature carburised AISI 316L austenitic stainless steel, Surface and Coatings Technology 202 (9) (2008) 1778-1784. doi:10.1016/J.SURFCOAT.2007.07.066.

[16] N. Agarwal, H. Kahn, A. Avishai, G. Michal, F. Ernst, A. Heuer, Enhanced fatigue resistance in 316L austenitic stainless steel due to low-temperature paraequilibrium carburization, Acta Materialia 55 (16) (2007) 5572-5580. doi:10.1016/J.ACTAMAT.2007.06.025.

[17] S. Leuders, T. Lieneke, S. Lammers, T. Tröster, T. Niendorf, On the fatigue properties of metals manufactured by selective laser melting The role of ductility, Journal of Materials Research 29 (17) (2014) 1911-1919. doi:10.1557/jmr.2014.157.

[18] A. B. Spierings, T. L. Starr, K. Wegener, Fatigue performance of additive manufactured metallic parts, Rapid Prototyping Journal 19 (2) (2013) 88-94. doi:10.1108/13552541311302932.

[19] Y.-L. Lee, Fatigue testing and analysis: theory and practice, Elsevier Butterworth-Heinemann, 2005.

[20] O. Fergani, A. Bratli Wold, F. Berto, V. Brotan, M. Bambach, Study of the effect of heat treatment on fatigue crack growth behaviour of 316L stainless steel produced by selective laser melting, Fatigue \& Fracture of Engineering Materials \& Structures 41 (5) (2018) 1102-1119. doi: $10.1111 /$ ffe. 12755 .

[21] M. Zhang, C. N. Sun, X. Zhang, P. C. Goh, J. Wei, D. Hardacre, H. Li, Fatigue and fracture behaviour of laser powder bed fusion stainless steel 316L: Influence of processing parameters, Materials Science and Engineering A 703 (April) (2017) $251-261$. doi:10.1016/j.msea.2017.07.071.

[22] I. 3D Systems, LaserForm 316L (A), Tech. rep. (2017).

URL https ://www. 3dsystems . com/materials/laserform-stainless-3161

[23] B. Van Hooreweder, Development of Accelerated Multi-axial Fatigue Tests Based on Scaling Laws (Ontwikkeling van versnelde multi-axiale levensduurtesten op basis van schaalwetten), PhD Thesis, KU Leuven, Belgium (2013).

[24] D. Wang, C. Song, Y. Yang, Y. Bai, Investigation of crystal growth mechanism during selective laser melting and mechanical property characterization of 316L stainless steel parts, Materials and Design 100 (2016) 291-299. doi:10.1016/j.matdes.2016.03.111.

[25] J.-Y. Huang, J.-J. Yeh, S.-L. Jeng, C.-Y. Chen, R.-C. Kuo, High-Cycle Fatigue Behavior of Type 316L Stainless Steel, Tech. rep.

[26] S. Kocanda, Fatigue failure of metals, Sijthoff \& Noordhoff International, 1978.

[27] D. Radaj, M. Vormwald, Advanced methods of fatigue assessment, Vol. 9783642307, Springer Science \& Business Media, Berlin, Heidelberg, 2013. doi:10.1007/978-3-642-30740-9.

[28] J. Schijve, Fatigue of Structures and Materials, second edition Edition, Springer Science \& Business Media, 2009. doi:10.1007/0-306-483963.

[29] T. DebRoy, H. Wei, J. Zuback, T. Mukherjee, J. Elmer, J. Milewski, A. Beese, A. Wilson-Heid, A. De, W. Zhang, Additive manufacturing of metallic components-process, structure and properties, Progress in Materials Science 92 (2018) 112-224.

[30] A. Riemer, S. Leuders, M. Thöne, H. A. Richard, T. Tröster, T. Niendorf, On the fatigue crack growth behavior in 316L stainless steel manufactured by selective laser melting, Engineering Fracture Mechanics 120 (2014) 15-25. doi:10.1016/j.engfracmech.2014.03.008.

[31] S. S. Manson, M. H. Hirschberg, The role of ductility, tensile strength and fracture toughness in fatigue, Journal of the Franklin Institute 290 (6) (1970) 539-548. doi:10.1016/0016-0032(70)90236-X. 
[32] B. Vrancken, Study of Residual Stresses in Selective Laser Melting, PhD Thesis, KU Leuven, Belgium (2016). doi:10.1007/s11277-0050744-1.

[33] J. P. Kruth, L. Froyen, J. Van Vaerenbergh, P. Mercelis, M. Rombouts, B. Lauwers, Selective laser melting of iron-based powder, Journal of Materials Processing Technology 149 (1-3) (2004) 616-622. arXiv:arXiv:1011.1669v3, doi:10.1016/j.jmatprotec.2003.11.051.

[34] A. Mirzaee-Sisan, C. E. Truman, D. J. Smith, M. C. Smith, Interaction of residual stress with mechanical loading in a ferritic steel, Engineering Fracture Mechanics 74 (17) (2007) 2864-2880. doi:10.1016/j.engfracmech.2006.12.033.

[35] J. Suryawanshi, K. G. Prashanth, U. Ramamurty, Tensile, fracture, and fatigue crack growth properties of a 3D printed maraging steel through selective laser melting, Journal of Alloys and Compounds 725 (2017) 355-364. doi:10.1016/j.jallcom.2017.07.177.

[36] T. Bolinder, I. Sattari-Far, J. Faleskog, Evaluation of the Influence of Residual Stresses on Ductile Fracture, in: ASME 2011 Pressure Vessels and Piping Conference: Volume 6, Parts A and B, ASME, 2011, pp. 347-356. doi:10.1115/PVP2011-58080. 